\title{
Fake news: the impact of the internet on population health
}

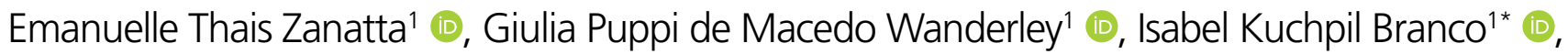

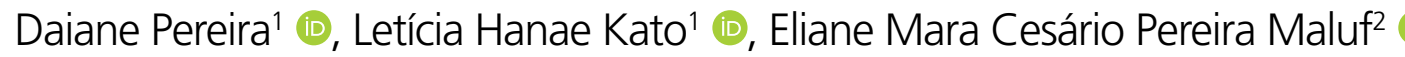

\section{SUMMARY}

OBJECTIVE: The aim of this study was to evaluate the search for health information on the Internet and to determine the frequency and main means of spreading fake health news.

METHODS: A descriptive cross-sectional study was conducted through the virtual distribution of questionnaires on social media platforms in 2019 by using the snowball technique. The questionnaire collected information regarding sociodemographics, means used to clarify doubts about health, implementation of information obtained through the Internet, receipt of fake news, and means of transmission of fake news. Quantitative variables are described as means and standard deviations, and categorical variables are described as frequencies and percentages. The chi-square and Fisher's exact tests were used.

RESULTS: Out of 1,195 respondents, 53\% had followed Internet guidance without consulting a health professional, especially young people and individuals with low education levels $(p<0.05)$. The resources most used to answer questions about health were a physician $(78 \%)$ and Google $(51 \%)$, and searches using the latter were more predominant among younger age groups $(p<0.05)$. A large part of the sample (89.4\%) had received fake news, and the main means of receipt were Facebook and WhatsApp.

CONCLUSIONS: The Internet was the second most commonly used means to search for health information. A significant portion of the population adopts actions based on this information. The frequency of broadcasting fake news through this digital medium is high.

KEYWORDS: Internet. Social media. Online access to information. Misinformation.

\section{INTRODUCTION}

The Internet has democratized access to health information, increasing the autonomy of patients in their relationship with healthcare professionals. Known by some as the "Dr. Google" phenomenon, the online search for symptoms, diagnoses, and treatments by patients has caused fear due to the various misinformation that accompanies such searches ${ }^{1}$.

In this scenario, fake news is a cause for concern. Fake news is defined as intentionally false information that is similar to credible news but with the intent to manipulate the recipient and draw attention to its content ${ }^{2,3}$ by misinforming and/or obtaining advantages over certain populations ${ }^{3}$.

Fake news usually has a wide reach, especially when propagated over the Internet. People usually give in to the emotional or political appeals coming from negative news ${ }^{2}$. Negative news arouses greater interest than does optimistic news, and therefore, such news stories are shared quickly ${ }^{4}$. To induce greater credibility, these stories usually involve health professionals or institutions ${ }^{5}$.

According to PSafe (2018), a cybersecurity company, in its fifth Digital Security Report, health was the second most frequent target of fake news, accounting for $41.6 \%$ of all fake

${ }^{1}$ Universidade Positivo - Curitiba (PR), Brazil.

¿Universidade Federal do Paraná, Curitiba (PR), Brazil.

*Corresponding author: isabelkbranco@gmail.com

Conflicts of interest: the authors declare there are no conflicts of interest. Funding: none.

Received on May 07, 2021. Accepted on May 09, 2021. 
news ${ }^{2}$. Currently, there is an epidemic of fake news in Brazil, directly impacting public health, and this epidemic has motivated actions to combat disinformation. The Brazilian Ministry of Health has dedicated an exclusive page to this topic, Saúde sem Fake News (saude.gov.br/fakenews), which encourages people to send images or texts they have received via WhatsApp so that the information can be checked. Subsequently, the news is classified as true or false and posted on the page.

Given this scenario, the aim of this study was to evaluate the search for health information on the Internet by the population and to determine the frequency of receiving fake health news and main means by which fake news is propagated.

\section{METHODS}

This was a descriptive cross-sectional observational study. This study was approved by the Research Ethics Committee of the Universidade Positivo in 2019 (Opinion 3,496,815).

The data collection was performed in 2019 through the virtual distribution of questionnaires (Google Forms) on social media platforms. Brazilians who were older than 18 years and who agreed to participate in the study were included. The questionnaire collected information about sociodemographics, means to clarify doubts about health, implementation of information obtained through the Internet, receipt of fake news, and means of fake news transmission. Duplicate questionnaires were excluded. To reduce the risk of incomplete electronic forms, all fields were marked as "mandatory questions." The participants were informed that the data would be kept confidential.

To distribute the questionnaires, nonprobabilistic sampling (snowball technique) was used, a methodology that consists of the individuals selected by the researchers to propagate the questionnaire to their acquaintances, gradually increasing the sample size. To ensure sample diversity, the questionnaires were sent to people of different ages and with different professions. These participants were invited to spread the questionnaire among their groups with people of a similar profile, and so on, forming reference chains for the data collection.

The quantitative variables are presented as means and standard deviations, and the categorical variables are presented as frequencies and percentages. Statistical analyses were performed using the Statistical Package for the Social Sciences version $20.0^{\circledR}$ (SPSS Inc., Chicago, IL, USA) using the chi-square test and Fisher's exact test. The significance level was set at $\mathrm{p}<0.05$.

\section{RESULTS}

A total of 1,195 questionnaires were answered, of which $815(68.2 \%)$ were answered by women. The median age of the respondents was 35 years (minimum 18 and maximum 83 years). The young adult population was predominant, that is, 706 (59.1\%) individuals; 370 (30.9\%) were between the ages of 40 and 60 years, and $119(10 \%)$ were older than 60 years. Regarding origin, 935 (78.2\%) respondents were from Paraná, and $260(21.8 \%)$ were from other states.

Regarding education, 282 (23.6\%) respondents had complete or incomplete elementary or high school education, and $913(76.4 \%)$ had complete or incomplete higher education. Of the total, $235(19.7 \%)$ respondents were students, 176 $(14.7 \%)$ were health professionals, and $750(62.8 \%)$ were professionals from other areas.

The majority, $929(77.7 \%)$, stated that they go to the physician to clarify doubts about health, $609(51 \%)$ stated that they consult Google, 219 (18.3\%) stated that they resort to friends, $167(14 \%)$ stated that they seek information in Basic Health Units, and 104 (8.7\%) stated that they look for information on government websites. It was possible to include more than one source of information in the responses. The younger the age group, the greater was the use of Google. In turn, physicians were more sought after by older individuals $(\mathrm{p}<0.05)$ (Figure 1).

To answer health questions, women sought the opinion of physicians more than did men $(79.8$ versus $73.4 \%$, $\mathrm{p}=0.017)$, while men used Google more than women $(56.8$ versus $48.2 \%, \mathrm{p}=0.006$ ). People with higher education levels sought the opinion of physicians more $(\mathrm{p}<0.001)$. There was no positive association between education level and seeking health information on social networks and Google ( $\mathrm{p}=0.734$ and $\mathrm{p}=0.454$, respectively).

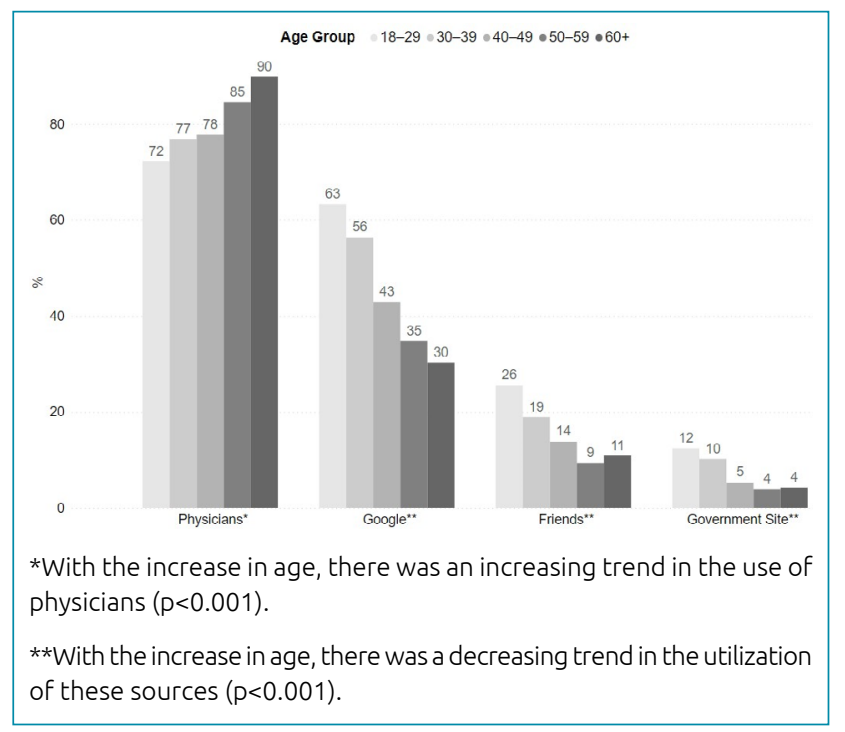

Figure 1. Distribution of health information search sources by age group $(n=1,195)$. 
Of the total participants, 638 (53.4\%) had followed health guidance from social networks without consulting a professional in the field, and 190 (15.9\%) had not followed any medical guidance because of the social network content. Regarding health-related behaviors, young people were more influenced by news found on the Internet (Figure 2).

Individuals with an education that did not exceed the high school level followed information obtained on the Internet without consulting a professional more often than did individuals with higher education $(\mathrm{p}=0.029)$.

The majority of the respondents, $888(74.3 \%)$, claimed to verify the sources of health news received. Health professionals claimed to verify these sources more than did other professionals ( 83.1 versus $72.9 \%, \mathrm{p}<0.001$ ), and people with higher education claimed to verify these sources more than did those with a lower level of education (77.7 versus $63.5 \%, \mathrm{p}<0.001)$.

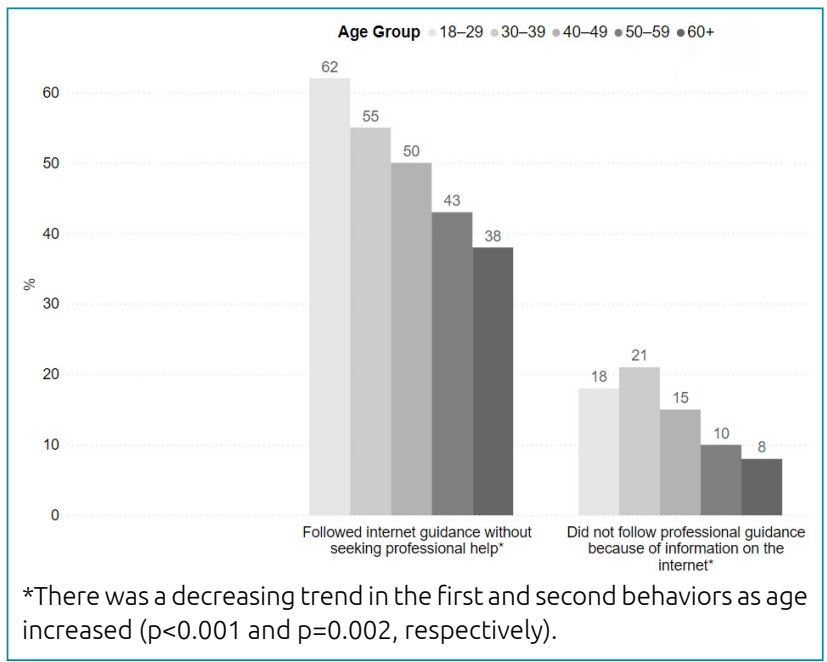

Figure 2. Actions taken by the population regarding health information obtained through the Internet by age group $(n=1,195)$.

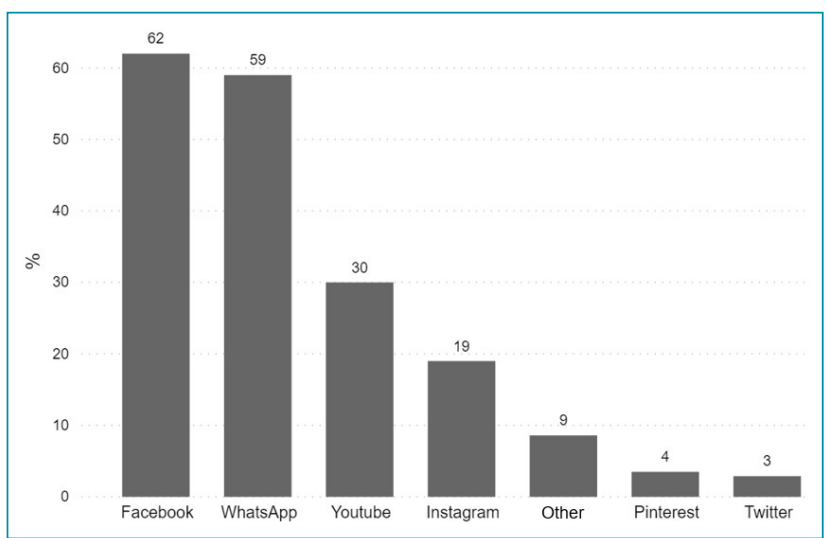

Figure 3. Percentage distribution of the source of fake news by social media platform $(n=1,069)$.
Most of the respondents, 1,069 (89.4\%), received some fake news about health. The main routes of receipt are shown in Figure 3. Facebook was the main source for younger respondents ( $\mathrm{p}=0.015)$, and WhatsApp was the main source for older respondents $(\mathrm{p}=0.005)$.

Only $9(0.7 \%)$ respondents had never heard about "fake news," while 1,081 (90.5\%) were unaware of the Saúde sem Fake News tool. Health professionals showed greater knowledge of this resource than did other professionals (16.4 versus $8.1 \%, \mathrm{p}=0.0017)$.

\section{DISCUSSION}

Physicians were the source most consulted among the respondents to answer questions about health. Women reported contacting a physician to answer their questions more frequently than did men, a finding that is consistent with the Brazilian reality, where health services are more commonly used by women. This is due, among other factors, to the various sociocultural and institutional barriers that hinder men from seeking health services ${ }^{6}$.

However, the Internet is an important vehicle for health information and has been increasingly used. In this study, there was a worrying trend among young people regarding a reduction in the use of physicians as sources of health information and a significant increase in Google searches. This could be explained by the higher occurrence of chronic diseases in the elderly population and consequently more frequent medical follow-ups. In addition, this portion of the population has greater difficulty finding this information on the Internet ${ }^{7}$. The behavior of young people, in turn, is probably due to greater contact with technology, leading to greater confidence in using online tools. This finding suggests that with the aging of this population, the search for information on the Internet will tend to increase and will become frequent even among future elderly individuals.

The data show that the greater the use of the Internet, the lower is the inclination to seek a physician and the higher are self-medication levels ${ }^{7}$. This is consistent with what was found in this study, as among those who reported having followed Internet guidance without consulting a health professional, the majority were young people.

People with a lower level of education also more frequently followed guidance obtained on the Internet without consulting health professionals. This can be explained by the lower access to health services by this portion of the population ${ }^{8}$.

If reliable sources are used, the search for health information on the Internet may have benefits, such as a greater understanding by the patient about the treatment and prevention 
of diseases ${ }^{9}$. However, it can lead to increased self-diagnoses, leading to erroneous conclusions and impairment in the physician-patient relationship ${ }^{10}$. It can also cause anxiety, increased medicalization, instrumentalization, and overdiagnosis among patients ${ }^{10}$. Also concerning is the increase in self-medication, its various side effects, and its interference with prescribed treatments?

The percentage of respondents who had received proven fake health news was high (89.4\%). In Brazil, the impact of fake news can be observed in the low adherence to vaccination campaigns, as occurred from 2016 to 2018 with the yellow fever and measles vaccines, which lead to new outbreaks of these diseases ${ }^{5}$, and during the COVID-19 pandemic in 2020/21, when several ineffective treatments were disseminated $^{3}$. In addition, fears caused by false information can lead to reduced adherence to treatment and scientifically proven diagnostic methods ${ }^{11}$.

PSafe (2018) reported that the three main platforms for the dissemination of fake news are WhatsApp, Internet browsers, and Facebook. In agreement with these data, the most frequent means of the dissemination of fake health news found in this study were Facebook and WhatsApp; these platforms are easy to access and facilitate the creation and sharing of content, in addition to being the most currently accessed media platforms ${ }^{2,11}$. The lack of monitoring of what is posted and limited media education among users also facilitates the dissemination of fake news ${ }^{11}$.

Given that the Internet has become one of the main resources for searching health information and that fake news is increasingly present on the Internet, it is essential to develop strategies for the safe use of these technologies. Coordinated actions among health professionals, governments, fact-checkers, and social media platforms are necessary ${ }^{12}$.

The Ministry of Health adopted an important action in the fight against fake news by creating Saúde sem Fake News in 2018. However, our study showed that only $9.5 \%$ of participants and only $16.4 \%$ of health professionals knew about this channel.
Investment in media education and awareness campaigns about fake news is extremely important. Another suggestion is to reduce the priority of sites that are sources of fake news by search engines, leading to less views of these publications ${ }^{13}$.

As fake news feeds on the distrust of people regarding medicine and science, it is important to strengthen the physician-patient relationship. For this, professionals must use language accessible to the population, be open to clarify doubts, and provide their patients with reliable sources to search for health information on the Internet ${ }^{5,9}$.

One of the limitations of this study is that the sample was not completely representative of the Brazilian population. There was a predominance of respondents with higher education. Due to this, it is possible that this study underestimated the influence of the Internet on the health of the population because people with less education were those who most followed information from the Internet.

\section{CONCLUSIONS}

Young people mostly used the Internet to learn about health. A large proportion of the population implements advice found on the Internet without consulting a physician (53.4\%), especially people with low education levels and young people, and this behavior can have harmful consequences on health.

The percentage of people who had received fake health news, mainly through Facebook and WhatsApp, was quite high $(89.4 \%)$. Faced with this increasingly worrying scenario, it is necessary to invest in the dissemination and implementation of services and measures to combat fake news.

\section{AUTHORS" CONTRIBUTIONS}

ETZ, GPMW, IKB: Project conceptualization, Methodology, Data curation, Formal analysis, Investigation, Writing - original draft, Writing - review \& editing. LHK, DP: Project conceptualization, Methodology, Data curation. EMCPM: Project conceptualization, Methodology, Project administration, Supervision, Validation.

\section{REFERENCES}

1. Lee K, Hoti K, Hughes JD, Emmerton L. Dr Google is here to stay but health care professionals are still valued: an analysis of health care consumers' internet navigation support preferences. J Med Internet Res. 2017;19(6):e210. https://doi.org/10.2196/jmir.7489

2. Souza AH, Souza CFOBA, Manhães FC, Tiradentes JFVN, Quarto LC. Um estudo bibliográfico sobre as fake news no âmbito da saúde. In: Silva MP, editor. Produção, comunicação e representação do conhecimento e da informação. Ponta Grossa: Atena; 2020. p. 139-45. https://doi.org/10.22533/at.ed.14620130211
3. Sousa Júnior JH, Raasch M, Soares JC, Ribeiro LVHAS. Da desinformação ao caos: uma análise das fake news frente à pandemia do coronavírus (COVID-19) no Brasil. Cadernos de Prospecção. 2020;13(2COVID-19):331-46. http://dx.doi. org/10.9771/cp.v13i2.COVID-19.35978

4. Pulido CM, Ruiz-Eugenio L, Redondo-Sama G, Villarejo-Carballido B. A new application of social impact in social media for overcoming fake news in health. Int J Environ Res Public Health. 2020;17(7):1-15. https://doi.org/10.3390/ijerph17072430 
5. Teixeira A. Fake news contra a vida: desinformação ameaça vacinação de combate à febre amarela [dissertação]. São Paulo: Pontifícia Universidade Católica de São Paulo; 2018.

6. Siqueira BPJ, Teixeira JRB, Neto PFV, Boery EM, Boery RNSO, Vilela $A B A$. Homens e cuidado à saúde nas representações sociais de profissionais de saúde. Esc Anna Nery Rev Enferm. 2014;18(4):690-6. http://dx.doi.org/10.5935/14148145.20140098

7. Van Riel N, Auwerx K, Debbaut P, Van Hees S, Schoenmakers $B$. The effect of Dr Google on doctor-patient encounters in primary care: a quantitative, observational, cross- sectional study. BJGP Open. 2017;1(2):1-10. https://doi.org/10.3399/ bjgpopen $17 \times 100833$

8. Nunes BP, Thumé E, Tomasi E, Duro SMS, Facchini LA. Desigualdades socioeconômicas no acesso e qualidade da atenção nos serviços de saúde. Rev Saude Publica. 2014;48(6):968-76. https://doi.org/10.1590/S00348910.2014048005388
9. Manso MEG, Vallada IBP, Hluchan K, Oshiro LVS. Fake news e saúde da pessoa idosa. Rev Longeviver. 2019;1(2):19-25.

10. Jutel A. "Dr. Google" and his predecessors. Diagnosis (Berl). 2017;4(2):87-91. https://doi.org/10.1515/dx-2016-0045

11. Junqueira $\mathrm{AH}$. Fake news na prescrição online de dietas alimentares: curandeirismo digital, negócios e riscos. VI Conferência do Pensamento Comunicacional Brasileiro; 2019; São Paulo; 2019. [cited on July 20, 2021]. Available from: https://portalintercom. org.br/anais/pensacom2019/textos/antonio-helio-junqueira.pdf.

12. Brennen JS, Simon F, Howard PN, Nielsen RK. Types, sources, and claims of COVID-19 misinformation . Oxford: Reuters Institute for the Study of Journalism; 2020 [cited on July 5, 2020]. Available from: https://reutersinstitute.politics.ox.ac. uk/types-sources-and-claims-covid-19-misinformation.

13. Waszak PM, Kasprzycka-Waszak W, Kubanek A. The spread of medical fake news in social media - the pilot quantitative study. Health Policy Technol. 2018;7(2):115-8. https://doi. org/10.1016/j.hlpt.2018.03.002 